\title{
Modification of The Physical and Chemical Properties of Formaldehyde by The Addition of The Glass-fiber
}

\author{
A.M. Ramadan, A.A. Amer* and A.F. Younan ${ }^{* *}$ \\ Faculty of Science-Helwan University, ${ }^{*}$ Ministry of Military \\ Production and ${ }^{* *}$ National Research Center, Cairo, Egypt.
}

\begin{abstract}
B ROMO-NOVOLAC (BN) is prepared via condensation polymerization of Bromophenol with formaldehyde using oxalic acid as a catalyst. Epichlorohydrine was further reacted in basic medium to form Epoxy-Bromo-Novolac (EBN). FT-IR confirmed the preparation of $\mathrm{BN}$ and $\mathrm{EBN}$. EBN is added to the commercial glass fiber, which was produced as sheets filled with polyester to be connected, the hardeners used were novolac- resolehexamethylenediamine HMDA with ratios $10,20,30 \%$ of the total added resin weight. A strong composite material was formed (Glass fiber enforced with epoxy bromo novolac).
\end{abstract}

The mechanical properties showed that the used $30 \%$ hardener HMDA gave an elastic and strong composite material with the resin. Chemical resistance test showed that the composite material is very inert high $\mathrm{pH}$ tolerance and high organic solvents resistance. The EBN glass fiber showed enhanced heat resistance over the original resin especially at elevated temperature higher than $350^{\circ} \mathrm{C}$.

Phenol formaldehyde resins (PF) are synthetic polymers obtained by the reaction of phenol or substituted phenol with formaldehyde. Phenolic resins are mainly used in the production of circuit boards. However they are better known for the production of molded products including pool balls, laboratory countertops, and as coatings and adhesives ${ }^{(1,2)}$.

Phenolic resins with exceptional fire resistance properties are in continued demand for military and aerospace applications. Halogenated organic compounds exhibit good flame-retard properties. Thus, incorporation of bromine into the network structure of the phenolic resin is expected to enhance the flame retard property of the system.

PF resins are either Resole or Novolac; which are differentiated according to the ratio of phenol to formaldehyde in the polymerization recipe and the type of catalyst used.

Novolacs are phenol-formaldehyde resins with formaldehyde to phenol molar ratio of less than one. The polymerization is brought to completion using acid- 
catalyst such as Oxalic, Hydrochloric or Sulfuric acids. "Hexamine" is the hardener used to crosslink novolac, at temperature $>90^{\circ} \mathrm{C}$, where methylene and dimethylene amino crosslinks are formed.

Resoles are Base-catalyzed phenol-formaldehyde resins with formaldehyde to phenol ratio greater than one (usually around 1.5). The high cross-linking density this type of phenolic resin its hardness, good thermal and chemical stability. Resoles are referred to as "one step poly condensation resin" as they cure without a cross linker unlike novolacs which are considered a "two step poly condensation resins".

Epoxy resins have a wide range of applications, including metal coatings and structural adhesives ${ }^{(3)}$. Epichlorohydrin $(\mathrm{ECH})$ is a colorless liquid with a pungent, garlic-like odor, moderately soluble in water, but miscible with most polar organic solvents ${ }^{(4)}$.

Fiberglass ${ }^{(5-8)}$ is a lightweight, extremely strong, and robust material, used in many products. Although strength properties are somewhat lower than carbon fiber and it is less stiff, the material is typically far-less brittle, and the raw materials are much less expensive. Its bulk strength and weight properties are also very favorable when compared to metals, and it can be easily formed using molding processes.

The term "fiberglass" technically refers to glass that can be pulled into long, thin fibers although it is also commonly used in reference to plastics reinforced with these fibers. Fiberglass is made primarily of silica (silicon dioxide, $\mathrm{SiO}_{2}$ ) but contains some percentage of other oxides that modify its properties for a particular application. Common fiberglass modifiers are calcium oxide $(\mathrm{CaO})$, magnesium oxide $(\mathrm{MgO})$, aluminum oxide $\left(\mathrm{Al}_{2} \mathrm{O}_{3}\right)$ and boron oxide $\left(\mathrm{B}_{2} \mathrm{O}_{3}\right)$. The chemical formula depends on the ratios of the different compounds used ${ }^{(9-11)}$.

Common uses of fiberglass include high performance aircraft (gliders), boats, automobiles, baths, hot tubs, septic tanks, water tanks, roofing, pipes, cladding, casts, surfboards and external door skins.

\section{Experimental}

\section{Chemicals used}

Phenol - Bromo Phenol - Formaldehyde 40\% - Oxalic acid - Sodium hydroxide - Epichlorohydrine - Hexamethylene-diamine - Methanol - Acetone Polyester - Sulforic acid - Sodium carbonate - Benzene - Sodium chloride.

\section{Preparation}

A- Preparation of Bromo - phenol formaldehyde resin $\left(\right.$ Bromo-novolac) ${ }^{(12,13)}$ 


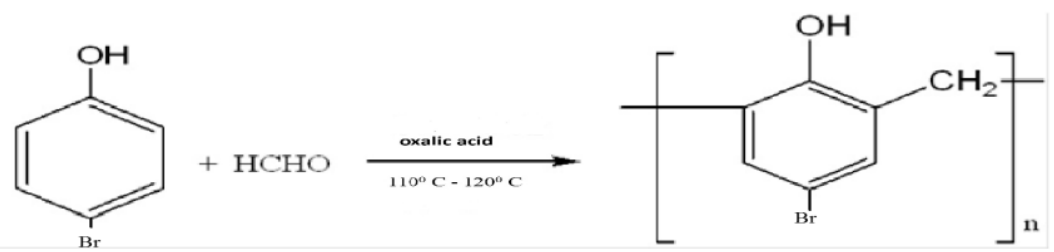

Fig. 1. preparation of bromo novolac.

Bromo phenol (0.72 mole) and formalin ( 0.6 mole) were mixed with oxalic acid as catalyst, the mixture was warmed continuously under reflux by means of low heating mantel applied directly to the flask where the exothermic reaction begins, then burner is taken away and the mixture is allowed to boil on its own. The flask is heated to $\left(120^{\circ} \mathrm{C}\right)$ for at least two hours, then the heat is stopped and the product was poured immediately.

B-Preparation of $(P F)$ phenol formaldehyde resin $(\text { Resol })^{(12,13)}$<smiles>CC=Cc1cc(CO)cc(CC(C)C)c1O</smiles>

Fig.2. Preparation of Resol.

Addition of (0.58 mole) phenol, $(0.71$ mole $)$ of formalin and $(40 \% \mathrm{NaOH})$ as catalyst was done while attached to reflux condenser with a wire gauze. Firstly, the mixture was heated at $70^{\circ}$ for $15 \mathrm{~min}$ then strongly at $120^{\circ}$ to $30 \mathrm{~min}$ till the mixture seen to have a red viscous shape on heating after the bubbles started to escape slowly and difficulty from the surface of the solution, then the heat source was removed and poured it immediately to another clean flask.

C-Preparation of phenol-formaldehyde (novolac) ${ }^{(12,13)}$.

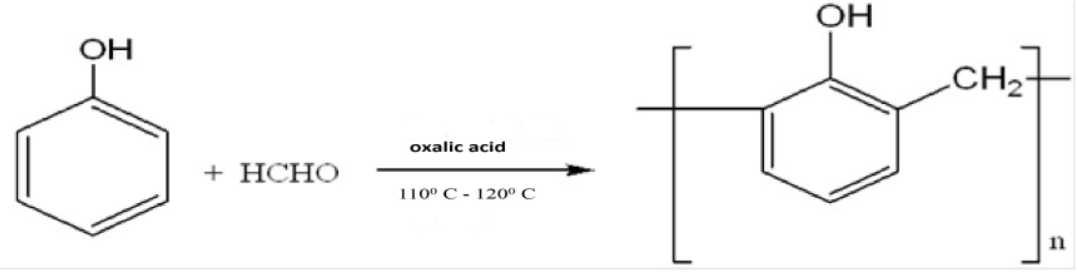

Fig. 3. Preparation of Novolac. 
Mix (0.7 mole) phenol and ( 0.59 mole) formalin with oxalic acid as a catalyst in a beaker, the mixture is warmed continuously under reflux by means of a low Bunsen flame applied directly to the flask as the exothermic reaction begins, the burner is taken away and the mixture was allowed to boil on its own, the flask is heated to $\left(120^{\circ} \mathrm{C}\right)$ for at least two to three hr, the heat is stopped and the Bunsen is taken away and the product is poured immediately in a separated beaker.

D-Preparation of Epoxy - bromo novolac ${ }^{(14)}$<smiles>CCc1cc(Br)cc(C)c1O</smiles><smiles>CC(C)(O)c1cc(Br)cc(CC2CO2)c1OCC1CO1</smiles>

Fig. 4. Preparation of epoxy bromo Novolac.

Condensation of $(0.06$ mole $)$ Bromo Novolac with $(0.12$ mole $)$ Epichlorohydrine in a three - necked round bottom flask, while with stirring, in presence of reflux condenser and dropping funnel $6 \mathrm{ml}$ of $\mathrm{NaOH} 0.05 \mathrm{M}$ was added to the reaction, while stirring and left for $30 \mathrm{~min}$ at $120^{\circ} \mathrm{C}$.

At the end of the reaction, $5 \mathrm{ml}$ water is added and the mixture is stirred for $20 \mathrm{~min}$ at $110^{\circ} \mathrm{C}$.

The resin is precipitated and the upper layer is decanted.

The resin is washed several times with distilled water till it gives no color with phenol phthalein.

Preparation of the coated samples

A sample containing three layers of glass fiber type (matrix 60) was prepared, sample dimensions $(10 \mathrm{~cm} \times 10 \mathrm{~cm})$ and then it was filled with polyester.

Nine samples were prepared of epoxy bromo novolac resin with different hardeners (novolac, resole, hexamethylene diamine), different ratios of hardeners $(10,20,30 \%)$ of total resin weight were added to form the material used as coats.

The coats were added to the prepared glass-fiber and kept three hours to get rid of the volatile contents. Temperature was adjusted to be less than $30^{\circ} \mathrm{C}$ during mixing and applying of the coat to the glass fiber sample. Glass plates with dimensions $(15 \mathrm{~cm} \times 5 \mathrm{~cm})$ were coated with $\mathrm{EBN}$ with different ratios of hardeners to run the chemicals resistance test.

Egypt. J. Chem. 58, No. 1 (2015) 


\section{Curing process}

The specimens were cured at $180^{\circ} \mathrm{C}$ for $45 \mathrm{~min}$.

Tests

Impact test results- (hardener HMDA - $30 \%$ of the total weight of the resin) ${ }^{(16)}$

Impact test: ASTM D-2794-93 (2010) "standard test method for resistance of organic coatings to the effects of rapid deformation": Coatings attached to substrates are subjected to damaging impacts during the manufacture of articles and their use in service. In its use over many years, this test method for impact resistance has been found to be useful in predicting the performance of organic coatings for their ability to resist cracking caused by impacts.

The test performed by dropping a weight of $1.8 \mathrm{~kg}$ from 1 meter height using (Instron - Wolfert machine) with an energy of $23.5 \mathrm{~J}$, angel of falling $30^{\circ}$. The enforced glass - fiber sample a cover for a metal rod with dimensions $(1 \mathrm{~cm} \times 1 \mathrm{~cm} \times 5 \mathrm{~cm})$.

Scratch hardness by pencil test- (hardener HMDA - 30\% of the total weight of the resin) $)^{(17)}$.

Hardness ASTM D3363-92a (2010) "standard test method for film hardness by pencil test": Pencil hardness measurements have been used by the coatings industry for many years to determine the hardness of clear and pigmented organic coating films. This test method has also been used to determine the cure of these coatings, especially when forced dried using heat. This test method is especially useful in developmental work and in production control testing in a single laboratory. It should be recognized that the results obtained may vary between different laboratories when different pencils as well as panels are used. Every effort should be made to standardize the hardness of the lead used and the technique followed.

Elongation test- (hardener HMDA - $30 \%$ of the total weight of the resin) ${ }^{(18)}$

Elongation test: ASTM D-522-930 (2013) "standard test methods for mandrel bend test of attached organic coatings": Coatings attached to substrates are elongated when the substrates are bent during the manufacture of articles or when the articles are abused in service. These test methods have been useful in rating attached coatings for their ability to resist cracking when elongated. They have been useful in evaluating the flexibility of coatings on flexible substrates.

This test is done by holding the sample from both sides and start to elongate it with increasing the force till the sample shows cracks and cuttings. The sample dimensions are $(5 \mathrm{~mm} \times 3 \mathrm{~cm} \times 17 \mathrm{~cm})$ while the machine used is united calibration corporation $(\mathrm{fm}-100)$ at section of polymers. 
The chemicals resistance test ${ }^{(19)}$

Chemicals resistance: ASTM D543-67 (2006) "standard practices for evaluating the resistance of plastics to chemical reagents": The limitations of the results obtained from these practices should be recognized. The choice of types and concentrations of reagents, duration of immersion or stress, or both, temperature of the test, and properties to be reported is necessarily arbitrary. The specification of these conditions provides a basis for standardization and serves as a guide to investigators wishing to compare the relative resistance of various plastics to typical chemical reagents.

Correlation of test results with the actual performance or serviceability of plastics is necessarily dependent upon the similarity between the testing and the end-use conditions. For applications involving continuous immersion, the data obtained in short-time tests are of interest only in eliminating the most unsuitable materials or indicating a probable relative order of resistance to chemical reagents.

Evaluation of plastics for special applications involving corrosive conditions should be based upon the particular reagents and concentrations to be encountered. The selection of test conditions should take into account the manner and duration of contact with reagents, the temperature of the system, applied stress and other performance factors involved in the particular application.

Thermal gravemetric analysis- (hardener HMDA - 30\% of the total weight of the resin)

Thermal gravimetric analysis (TGA) test for heat resistance and stability: Thermal gravimetric analysis or thermal gravimetric analysis (TGA) is a method of thermal analysis in which changes in physical and chemical properties of materials are measured as a function of increasing temperature (with constant heating rate), or as a function of time (with constant temperature and/or constant mass loss). TGA can provide information about physical phenomena, such as second-order phase transitions, including vaporization, sublimation, absorption, adsorption and desorption. Likewise, TGA can provide information about chemical phenomena including chemisorptions, desolvation (especially dehydration), decomposition and solid-gas reactions (e.g., oxidation or reduction).

\section{Results and Discussion}

\section{The infrared spectrum}

Figure 5, shows a characteristic absorption band of phenolic methylol hydroxyl group at $3504 \mathrm{~cm}^{-1}$. Methylene bridges between aromatic rings appear at $1450 \mathrm{~cm}^{-1}$ confirming the formation of $\mathrm{BN}$ resin. 


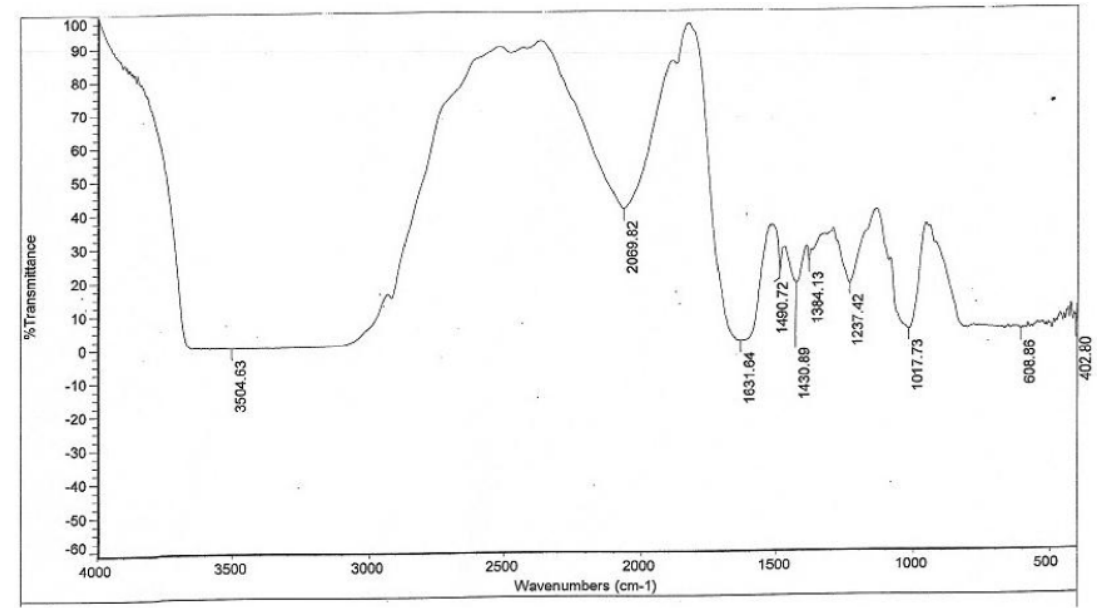

Fig. 5. Spectroscopy of bromo novolac.

Figure 6 shows the FTIR-spectra of EBN. It is evident from the figure that, there is a Broad band near $3450 \mathrm{~cm}^{-1}$ which is attributed to stretching vibration of the hydroxyl phenolic group. The absorption band near $2920 \mathrm{~cm}-1 \mathrm{might}$ be due to aliphatic $\mathrm{C}-\mathrm{H}_{2}$ vibrations. The absorption band near $1620 \mathrm{~cm}^{-1}$, is attributed to aromatic double bond. The absorption band at $1240 \mathrm{~cm}^{-1}$ indicates the presence of oxirane group. The regions of 750-790 and $820-850 \mathrm{~cm}^{-1}$ are due to $\mathrm{O}-, \mathrm{P}-$ and ring-substitution of phenolic ring, respectively.

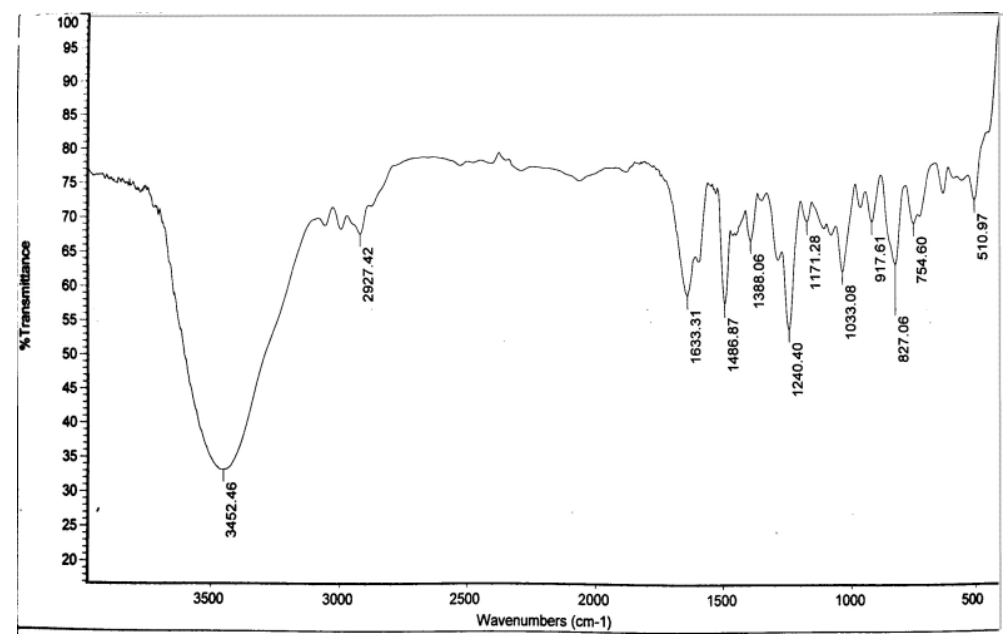

Fig. 6 . Spectroscopy of epoxy bromo novolac. 
Drying time ${ }^{(15)}$

Drying time was the main factor of choosing the HMDA as a hardener because it gave the best results as it clearly seen in Table 1.

TABLE 1. Drying time according to the hardeners used.

\begin{tabular}{|c|c|c|c|c|}
\hline \multicolumn{5}{|c|}{ Drying time } \\
\hline Resin & Hardener & Ratio \% & Time & Result \\
\hline EBN & Novolac & $\begin{array}{l}10 \\
20 \\
30\end{array}$ & $\begin{array}{c}\text { More than } 14 \\
\text { days } \\
\text { 9-10 days } \\
5 \text { days }\end{array}$ & $\begin{array}{c}\text { Not } \\
\text { recommended }\end{array}$ \\
\hline EBN & Resole & $\begin{array}{l}10 \\
20 \\
30 \\
\end{array}$ & $\begin{array}{c}\text { More than } 10 \\
\text { days } \\
8 \text { days } \\
5 \text { days } \\
\end{array}$ & $\begin{array}{c}\text { Not } \\
\text { Recommended }\end{array}$ \\
\hline EBN & HMDA & $\begin{array}{l}10 \\
20 \\
30 \\
\end{array}$ & $\begin{array}{c}3 \text { days } \\
24 \mathrm{hr} \\
5-8 \mathrm{hr}\end{array}$ & Recommended \\
\hline
\end{tabular}

The results revealed that using hexamethylene diamine hardener gave the best results than the other hardeners. The results also showed that $30 \%$ of HMDA of the total weight of the resin gave the best results. As the drying time increases it give more advantage for shaping the composite and forming it.

Impact test results- (hardener HMDA - 30\% of the total weight of the resin) ${ }^{(16)}$

Impact test: ASTM D-2794-93 (2010) "standard test method for resistance of organic coatings to the effects of rapid deformation"

The test performed by dropping a weight of $1.8 \mathrm{~kg}$ from 1 meter height using (Instron - Wolfert machine) with an energy of $23.5 \mathrm{~J}$, angel of falling $30^{\circ}$. The enforced glass - fiber sample a cover for a metal rod with dimensions $(1 \mathrm{~cm} \times 1$ $\mathrm{cm} \times 5 \mathrm{~cm}$ ). After falling, the metal was broken and the sample had no scratch, cut or any other physical change.

The sample passes the impact test due to the high flexibility and elasticity because of the formation of a high strength cross linkage. The sample showed after the collision high flexibility properties and retained its shape easily.

Scratch hardness by pencil test- (hardener HMDA - 30\% of the total weight of the resin) ${ }^{(17)}$

Hardness ASTM D3363-92a (2010) "standard test method for film hardness by pencil test"

The test is done by projecting a pencil hold firmly against a film of coated composite glass fiber sample put horizontally; at (45) angle and pushed away from the operator in $6.5 \mathrm{~mm}$ stroke. The process was started with the hardest pencil and continued down the scale of hardness $(6 \mathrm{H}-5 \mathrm{H}-4 \mathrm{H} 3 \mathrm{H}-2 \mathrm{H}-\mathrm{H}-\mathrm{F}-\mathrm{HB}-\mathrm{B}-$ 2B-3B-4B-5B-6B) of the pencil that will not scratch the film.

Egypt. J. Chem. 58, No. 1 (2015) 
The film hardness on a metallic plate was $(4 \mathrm{H})$.

The film hardness on the composite material was $(\mathrm{HB}),(\mathrm{H})$ and $(3 \mathrm{H})$ using 10,20 and $30 \%$ of hardener, respectively.

The results showed that using of coat on a metallic plate appeared to be very strong coating material than using it with the glass fiber which has been hardened with HMDA, this is may be attributed to the flexibility and the elasticity of the glass fiber. These results confirmed that the resin can be used as a strong coating material.

Elongation test- (hardener HMDA - $30 \%$ of the total weight of the resin) ${ }^{(18)}$

Elongation test: ASTM D-522-930 (2013) "standard test methods for mandrel bend test of attached organic coatings"

From Fig. 7 it can be seen that: The sample showed cracks at 2944 Newton, elongation at break was $68 \%$ and the yield elongation was $29 \%$. From the results, the sample needed $(2000 \mathrm{~N})$ to show any cracking or destruction. The destruction reason was due to layers separation which were connected with polyesters and resin in the composite material. This destruction may be enhanced by pressing the fiber layers and increasing their concentration.

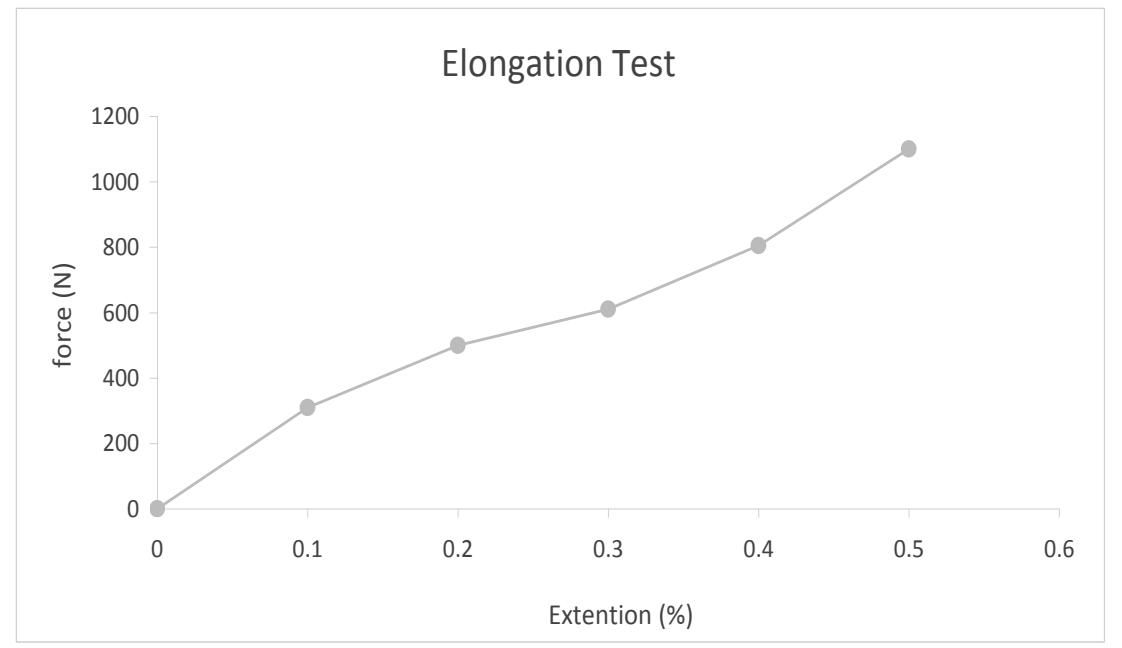

Fig. 7. Elongation test results.

The chemicals resistance test ${ }^{(19)}$

Chemicals resistance: ASTM D543-67 (2006) "standard practices for evaluating the resistance of plastics to chemical reagents"

This test can be carried out by dipping the enforced glass - fiber samples in different chemicals (acid - base - salt - solvents) for about 60 days and notice 
the change in the sample. The results are shown in Table 2, they showed that using 30\% HMDA hardener gives the best results due to the formation of the maximum cross linkage and making a very strong coating material which can resist acids, bases, salts and solvents.

TABLE 2. Chemicals resistance test results.

\begin{tabular}{|c|c|c|c|c|c|c|c|}
\hline \multirow{2}{*}{ Resin } & \multirow{2}{*}{$\begin{array}{c}\text { Hardener } \\
\text { ratio \% }\end{array}$} & $\begin{array}{c}\text { Glass } \\
\text { fiber } \\
\text { presence }\end{array}$ & $\begin{array}{c}\mathbf{H}_{\mathbf{2}} \mathbf{S O}_{\mathbf{4}} \\
\mathbf{1 0 \%}\end{array}$ & $\begin{array}{c}\mathbf{N a O H} \\
\mathbf{1 0 \%}\end{array}$ & $\begin{array}{c}\mathbf{N a}_{\mathbf{2}} \mathbf{C O}_{\mathbf{3}} \\
\mathbf{1 0 \%}\end{array}$ & $\begin{array}{c}\text { Sea } \\
\text { water }\end{array}$ & benzene \\
\hline \multirow{2}{*}{$\mathrm{EBN}$} & \multirow{2}{*}{10} & Yes & $\mathrm{G}$ & $\mathrm{F}$ & $\mathrm{F}$ & $\mathrm{G}$ & $\mathrm{G}$ \\
\cline { 3 - 9 } & & $\mathrm{No}$ & $\mathrm{G}$ & $\mathrm{F}$ & $\mathrm{F}$ & $\mathrm{G}$ & $\mathrm{G}$ \\
\hline \multirow{2}{*}{$\mathrm{EBN}$} & \multirow{2}{*}{20} & Yes & $\mathrm{G}$ & $\mathrm{G}$ & $\mathrm{G}$ & $\mathrm{E}$ & $\mathrm{G}$ \\
\cline { 3 - 9 } & & $\mathrm{No}$ & $\mathrm{G}$ & $\mathrm{G}$ & $\mathrm{G}$ & $\mathrm{G}$ & $\mathrm{G}$ \\
\hline \multirow{2}{*}{$\mathrm{EBN}$} & \multirow{2}{*}{30} & Yes & $\mathrm{G}$ & $\mathrm{G}$ & $\mathrm{G}$ & $\mathrm{E}$ & $\mathrm{E}$ \\
\cline { 3 - 9 } & & $\mathrm{No}$ & $\mathrm{G}$ & $\mathrm{G}$ & $\mathrm{G}$ & $\mathrm{E}$ & $\mathrm{E}$ \\
\hline
\end{tabular}

$\mathrm{E}=$ Excellent, $\mathrm{G}=\mathrm{Good}, \mathrm{F}=$ fair

Thermal gravemetric analysis- (hardener HMDA - 30\% of the total weight of the resin)

Thermal gravimetric analysis (TGA) test for heat resistance and stability

The TGA test is carried out by taking a few amount of the sample and exposed to heat, then recording time and weight till $600^{\circ} \mathrm{C}$. From the results shown in Fig. 8, the destruction starts at $230^{\circ} \mathrm{C}$, then it continues quickly till $340^{\circ} \mathrm{C}$ where the remaining residue is about $25 \%$, the slow rate of destruction was shown till $600^{\circ} \mathrm{C}$ where the remaining residue is $5 \%$.

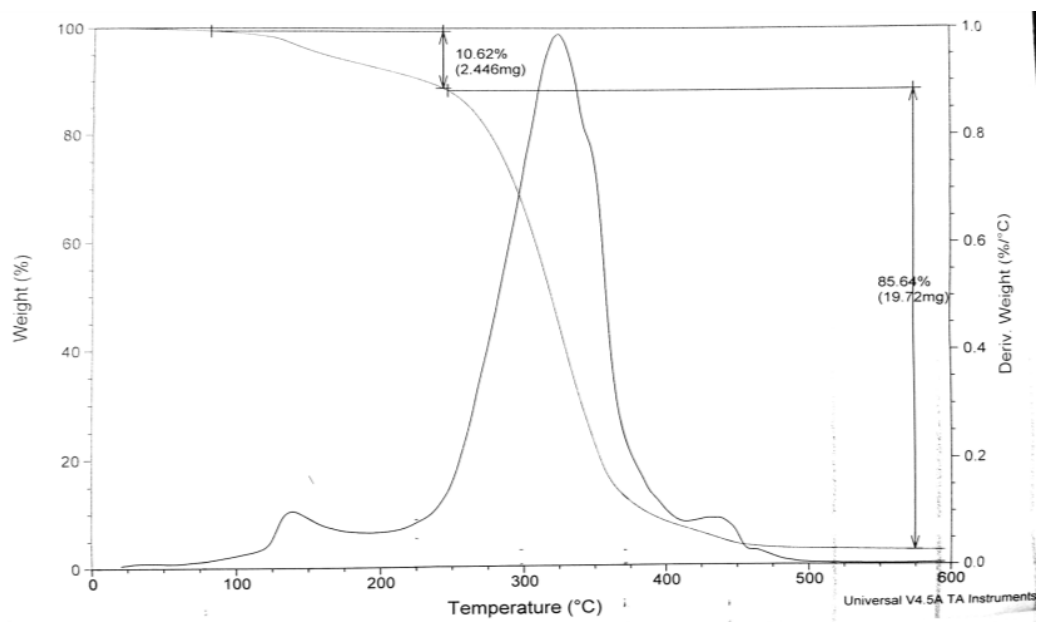

Fig. 8. TGA of epoxy bromo novolac.

Egypt. J. Chem. 58, No. 1 (2015) 
From the results shown in Fig. 9, the destruction starts at $230^{\circ} \mathrm{C}$ with slow rate, showing maximum loss between $230^{\circ} \mathrm{C}-375^{\circ} \mathrm{C}$ where about $43 \%$ is lost. The rate becomes slow again till $600{ }^{\circ} \mathrm{C}$ where the remaining residue $42 \%$ of the weight.

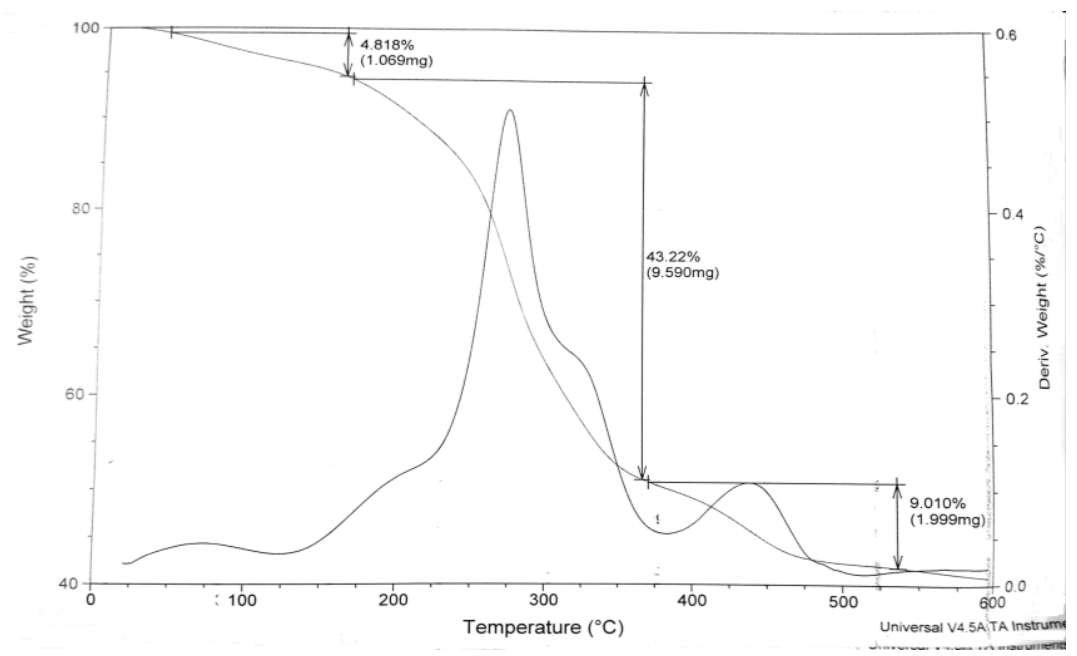

Fig. 9. TGA of epoxy bromo novolac with glass fiber.

\section{Conclusions}

The composite material has very strong resistance against the acids, solvents and sea water. While the basic medium showed its effect to the composite material before the acidic medium, solvents and sea water.

The composite material possesses high heat resistance due to the formation high cross linkage formed and the high resistance of glass fiber to heat. The composite material showed better results than the resin in the TGA test to $600{ }^{\circ} \mathrm{C}$, and its residue was about $40 \%$ of the starting weight, while the resin residue was about $2 \%$ of the starting weight.

The mechanical properties test showed high flexibility and elasticity of the composite material because of the formation of a high strength cross linkage between the resin and the glass fiber also it retained its shape easily after the collisions. Using the resin as a coat to metallic plates gave a strong material which can resist scratching, while using it with glass fiber gave an elastic material with strong coat with lower scratching resistance. The material showed elastic properties when it was elongated which is due to the presence of glass fiber and the elasticity of the resin which is an advantage to it against cracking and under strong force and elongation circumstances. These elastic properties gave it resistance to cracking and offered high elongation. 


\section{References}

1. Motawie, A.M. and Sadek, E.M., Journal of Applied Polymer Science, 70,1769 (1998).

2. Gardziella, A., Pilato, L.A. and Knop, A., Phenolic Resins: Chemistry, Applications, Standardization, Safety and Ecology, $2^{\text {nd }}$ ed, Springer (2000).

3. Marciano, M.A., Ordinola-Zapata, R., Cunha, T. V. R. N., Duarte, M. A. H., Cavenago, B. C., Garcia, R. B., Bramante, C. M., Bernardineli, N. and Moraes , I.G., Analysis of four gutta-percha techniques used to fill mesial root canals of mandibular molars. International Endodontic Journal, 44 (4), 321-329. doi: 10.1111/ j.1365-2591.2010.01832.x.PMID 21219361 (April 2011).

4. Robinette, E.J., Ziaee, S. and Palmese, G. R., Polymer, 45, 6143-6154 (2004).

5. Morena, J., John, Advanced Composite Mold Making. New York: Van Nostrand Reinhold Co. Inc. pp. 124-125 (1988).

6. Mayer, M. Rayner, Design with Reinforced Plastics, Springer, p. 7 (1993)

7. Nawy, G., Edward, Fundamentals of High-Performance Concrete (2 ${ }^{\text {nd }}$ ed.), John Wiley and Sons, p. 310 (2001).

8. Lubin, G., (Ed) Handbook of Composites, Van Nostrand Rheinhold Company, NewYork (1982).

9. Barry, Carter, C. and Grant, Norton, M., Ceramic Materials: Science and Engineering" (2007).

10. "Seymour/Carraher's, "Polymer Chemistry"; Charles E. Carraher, Raymond Benedict Seymour; (2003).

11. "Dictionary of Glass: Materials and Techniques"; Charles Bray (2001).

12. Braun, D., Cherdorn, H. and Ritter, H., "Polymer Synthesis" Theory and Practice, $3^{\text {rd }}$ ed, Springer-Verlag Berlin, Germany, pp. 245 (2001).

13. Motawie, A.M. and Sadek, E.M., Polymers for Advanced Technologies, 10, 223 (1999).

14. Motawie A.M. and Sadek, E.M., Journal of Applied Polymer Science, 70, 1769 (1998).

15. http://www.astm.org/Standards/D1640.htm.

16. http://www.astm.org/Standards/D2794.htm.

17. http://www.astm.org/Standards/D3363.htm.

18. http://www.astm.org/Standards/D522.htm.

19. http://www.astm.org/Standards/D543.htm. 


\section{تحوير الخواص الكيميائية والفيزيائية للفورمالدهيا بإضافة الفييز جلاس توبر

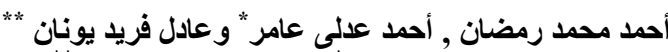

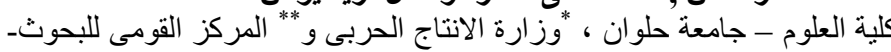

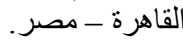

تستخدم راتتجات الفينول فورمالدهيد الان على نطاق واسع كمادة مقاومة للحرارة وذلك لقدرتها على تكوين شبكة ثلاثية الابعاد من الروالطي والط مع استخدام المادة

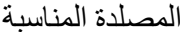

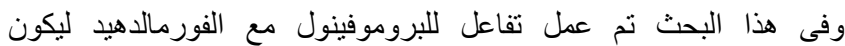

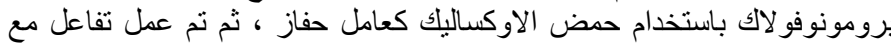

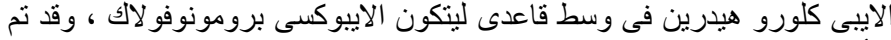

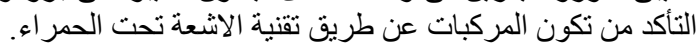

تم اضافة الر اتنج الى الالياف الزجاجية من النوع التجارى المسمى ماتريكس

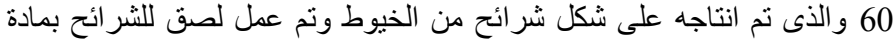

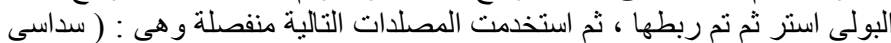

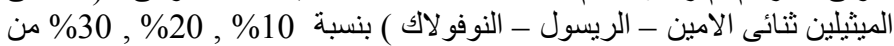

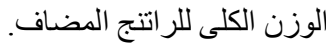

ثم تكونت مادة مركبة وهى الالياف الزجاجية المقواة بالبرومو ايبوكسى نوفو لاك.

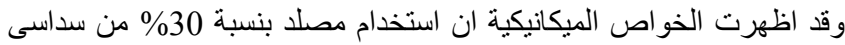

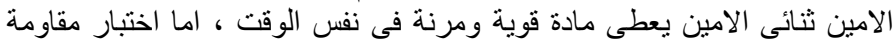

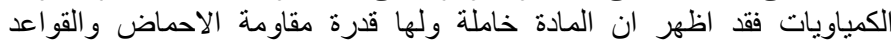

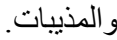

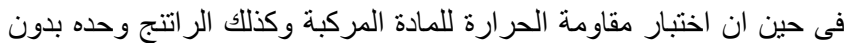

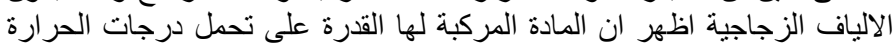

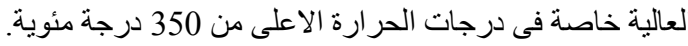

